\title{
The Gibberella fujikuroi niaD gene encoding nitrate reductase: isolation, sequence, homologous transformation and electrophoretic karyotype location
}

\author{
Bettina Tudzynski, ${ }^{1}$ Katrin Mende, ${ }^{1}$ Klaus-Michael Weltring, ${ }^{1}$ \\ James R. Kinghorn ${ }^{2}$ and Shiela E. Unkles ${ }^{2}$
}

Author for correspondence: Bettina Tudzynski. Fax: +49251833823.

1 Institut fur Botanik und
Botanischer Garten,
Westfalische Wihelms-
Universitat, D-48149
Munster, Germany
2 Plant Science Laboratory,
Sir Harold Mitchell
Building, School of
Biological and Medical
Sciences, University of St
Andrews, Fife KY16 9TH,
UK

\begin{abstract}
The Gibberella fujikuroi niaD gene, encoding nitrate reductase, has been isolated and used to develop an efficient homologous transformation system. A cosmid vector designated pGFniaD was generated based on niaD selection and shown to give comparable transformation efficiencies. Using PGFniaD, a genomic library was prepared and used for genetic transformations, giving frequencies of up to 200 transformants per $\mu \mathrm{g}$ DNA. Of 15 transformants analysed by Southern blots, six showed homologous integration whilst the remaining nine integrated at heterologous sites, indicating that the vector may be used reliably for both types of integration. The system therefore may be used both for self-cloning of gibberellin biosynthetic genes on the basis of complementation of defective mutants, and also for gene disruption experiments. Electrophoretic karyotype determination suggested at least 11 chromosomes ranging from 2 to $6 \mathrm{Mb}$, the total genome size being at least $37 \mathrm{Mb}$. The niaD gene was assigned to chromosome $\mathrm{V}$ by Southern blot analysis. The niaD gene is interrupted by one intron, and remarkably the promoter sequence, but not the $3^{\prime}$ untranslated sequence, is highly homologous to that of the corresponding Fusarium oxysporum gene. This situation appears to be unique with respect to the promoter regions of corresponding genes in related species of filamentous fungi.
\end{abstract}

Keywords: Gibberella fujikuroi, niaD gene, homologous transformation, electrophoretic karyotype, gene structure

\section{INTRODUCTION}

The ascomycetous filamentous fungus Gibberella fujikuroi is used to produce gibberellins (Bu'Lock et al., 1974), fungal hormones which are used commercially to elevate growth in higher plants, including agriculturally and horticulturally important species. In the fungus, gibberellins appear to promote elongation of hyphae and asexual spore germination. The gibberellins are complex structures: diterpenoids with a characteristic ring system. Gibberellins of commercial value, $G_{3}, G A_{4}$ and $G A_{7}$, are used in combinations as it is uneconomic to separate these molecules on an industrial scale (Vass \& Jeffries, 1979; Brückner \& Blechschmidt, 1991a, b). Although the

Abbreviation: GA, gibberellic acid.

The EMBL accession number for the sequence reported in this paper is X90699. fungal biosynthetic pathway for such molecules has been studied and reasonably well characterized biochemically (Pitel et al., 1971a, b; Hedden et al., 1978), there is less information regarding their genetics and molecular biology. The rather limited classical genetic research has yielded several gibberellin-non-producing mutants (Bearder, 1983; Avalos et al., 1994; Candau et al., 1991, 1992). Progress in the molecular genetics of $G$. fujikuroi has been made recently by the isolation of DNA clones encoding 3-hydroxy-3-methyl glutaryl-coenzyme A reductase, farnesyl pyrophosphate synthase and geranylgeranyl pyrophosphate synthase (B. Tudzynski and coworkers, unpublished) using DNA probes from other species. Other potential gibberellin biosynthetic genes have been isolated by differential display (Appleyard et al., 1995).

To further the study and understanding of the role played by these genes in gibberellin biosynthesis and to facilitate 
(a)

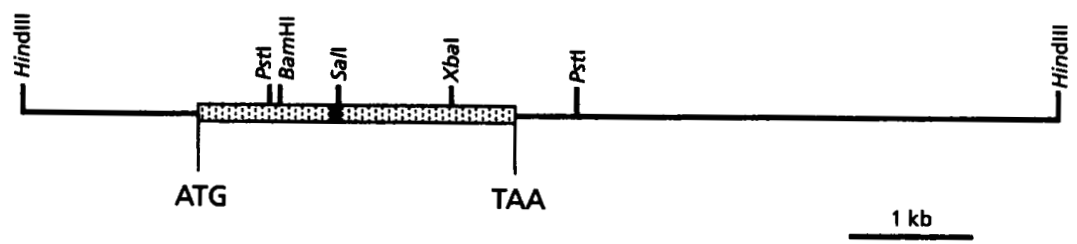

(b)

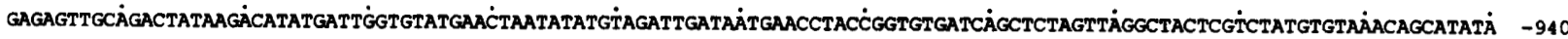

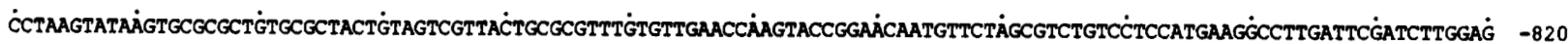

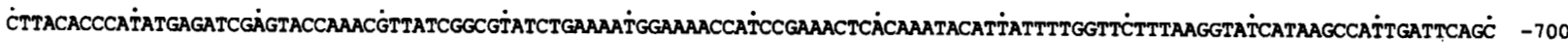

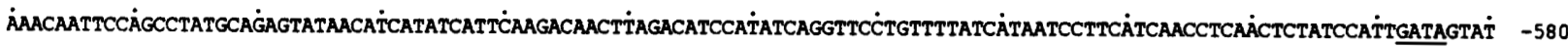

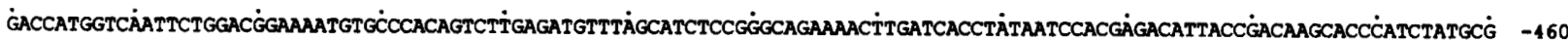

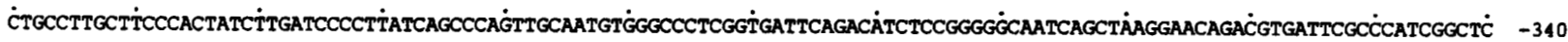

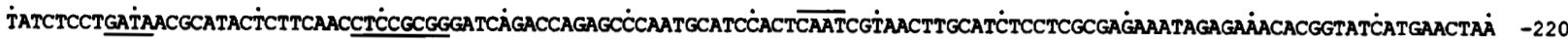

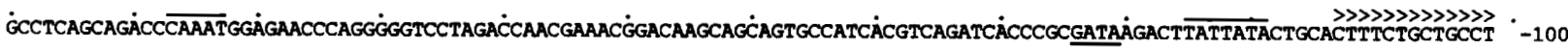

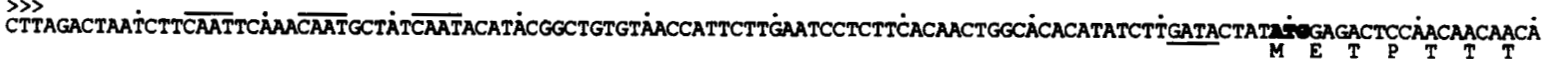

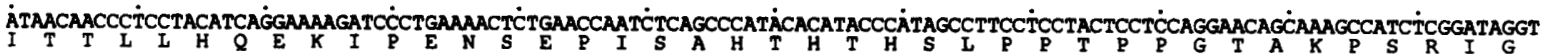

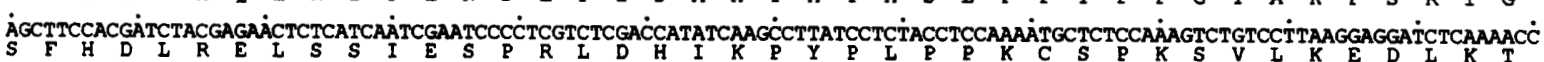

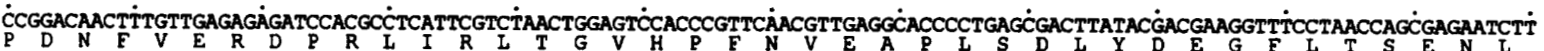

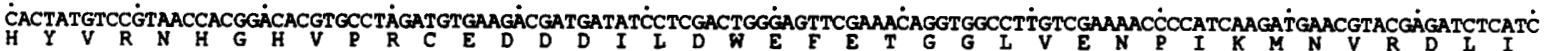

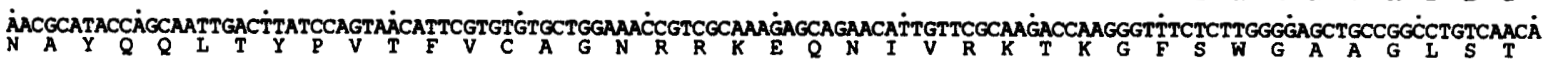

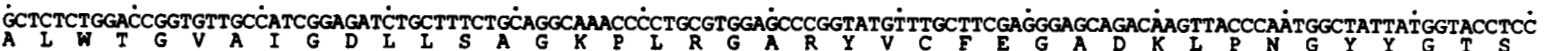

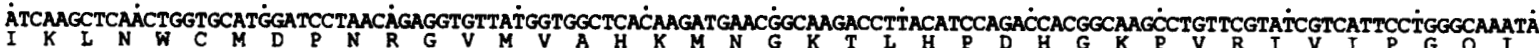

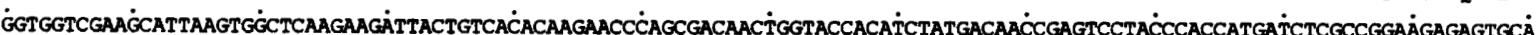

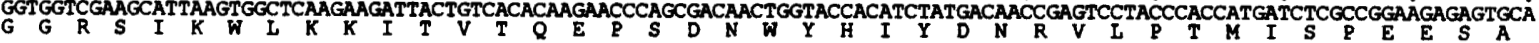

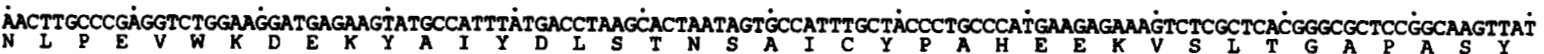

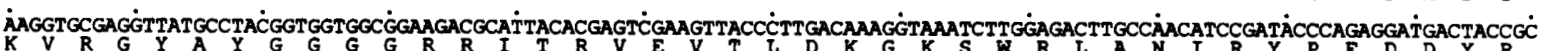

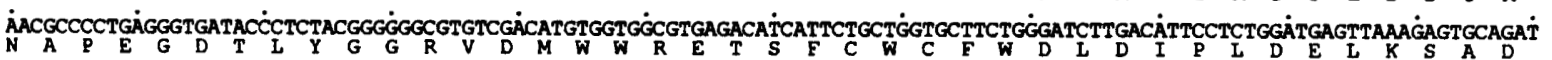

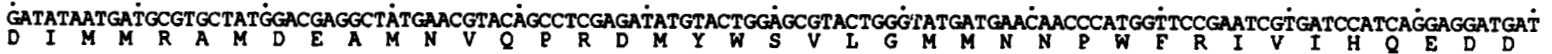

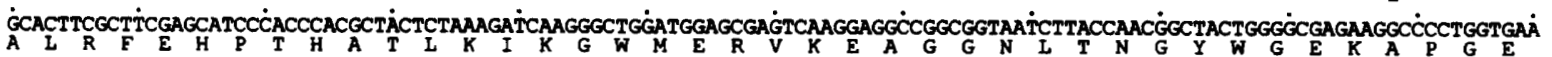

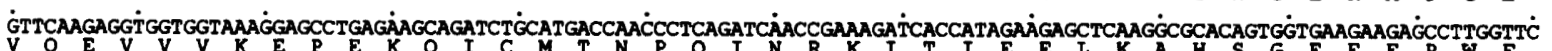
V Q E V V V K E P E K Q I C M T N P Q I N R K I T I E E I K A H S G E E E P W F

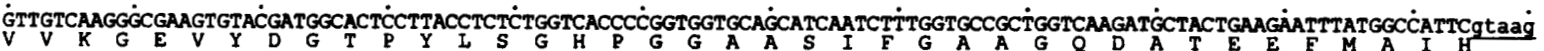
țcccacctaatcataccaagtccattcaaatgcccactaacatt tgcatcágACAGCGAGAATGCAAAAGCCATGTTGCC.

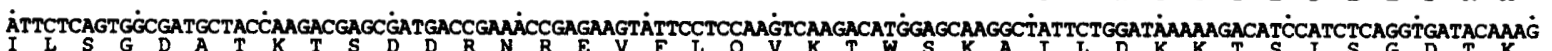

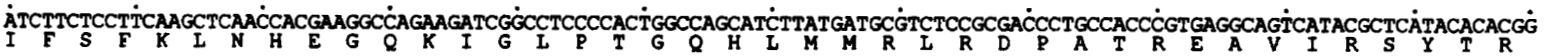
T.

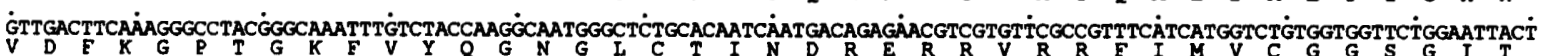

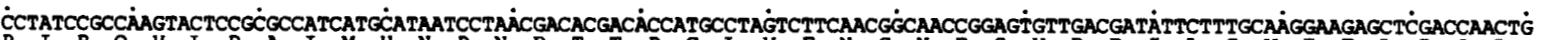

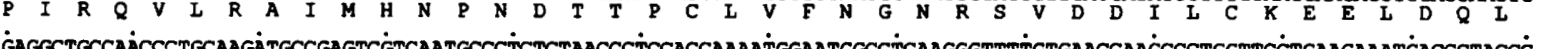

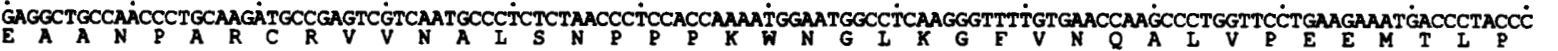

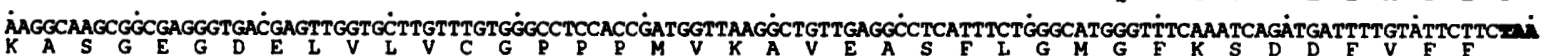

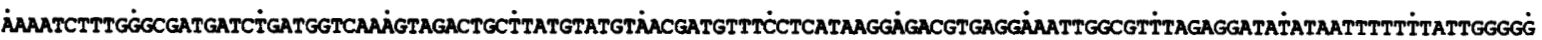

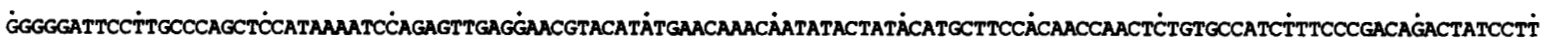


the isolation of further gibberellin-specific genes by complementation of GA-defective mutants, an efficient transformation system is required. In this regard, several attempts to develop genetic transformation have been carried out. Such studies report heterologous systems which yield low transformation frequencies of around 1-10 transformants per $\mu \mathrm{g}$ DNA (Sanchez-Fernandez et al., 1991; Brückner et al., 1992).

The aim of the work described here was to establish a reliable, efficient transformation system for $G$. fujikuroi and to obtain basic biological information about this important industrial fungus. We report the first homologous transformation for $G$. fujikuroi based on niaD, encoding nitrate reductase, its electrophoretic karyotype location and basic information on gene organization in G. fujikuroi.

\section{METHODS}

Strains and media. G. fujikuroi wild-type strain m567 was originally isolated from rice as a plant pathogen; it was obtained from the fungal strain collection, Weimar, Germany. The first G. fujikuroi mutant strain used in this study for transformation experiments was niaD57, isolated following ultraviolet mutagenesis of wild-type cells on medium containing $60 \mathrm{~g}$ $\mathrm{NaClO}_{3} \mathrm{l}^{-1}$, with $10 \mathrm{mM}$ glutamate as a sole nitrogen source (Cove, 1976; Klittich \& Leslie, 1988). It was classified as a niaD mutant as judged by its growth responses on various nitrogen sources. A second niaD mutation (niaD10) was generated in strain B1-41a to give strain B1-41a/10. Both strains (B1-41 a and B1-41a/10) are blocked in kaurene oxidase, the first step of gibberellin biosynthesis (Bearder, 1983).

Standard DNA manipulation procedures. Strains were grown on Gibberella complete medium as described by Brückner $e t$ al. (1992). Genomic DNA and DNA from lambda phage was isolated according to standard procedures (Sambrook et al., 1989) and plasmid DNA following the Qiagen protocol.

Electrophoretic karyotype determination. The method used was basically that of Smith et al. (1987) and Brody \& Carbon (1989). Aliquots containing $10^{8}$ protoplasts were embedded in low-melting-point agarose and their chromosomes separated by PFGE using Biometra Rotaphor electrophoresis equipment. The following chromosomal separation conditions were employed: $2 \mathrm{~h}, 600 \mathrm{~s}$ constant switching interval $140-150^{\circ} \mathrm{log}$, $48 \mathrm{~V}$, speed $5 ; 200 \mathrm{~h}, 9000-500 \mathrm{~s}$ decreasing switch interval, $110-98^{\circ}, 48-42 \mathrm{~V}, 10^{\circ} \mathrm{C}$. DNA was blotted on to Hybond nylon membrane and Southern blot analysis was performed using the $8.8 \mathrm{~kb}$ HindIII DNA fragment (Fig. 1a) carrying the niaD gene of $G$. fujikuroi. Prehybridization $(5 \mathrm{~h})$, hybridization $(14 \mathrm{~h})$ and washing $(2 \times \mathrm{SSC}, 0 \cdot 1 \% \mathrm{SSC})$ were performed at $60^{\circ} \mathrm{C}$ in a shaking water bath. Filters were exposed using Kodak $\mathrm{X}$-ray film at $-70^{\circ} \mathrm{C}$ for $7 \mathrm{~d}$.

Transformation procedure. The procedure for generation of protoplasts and transformation was essentially that described by Brückner et al. (1992). Protoplasts incubated with the various plasmids and cosmids were added to molten Czapek-Dox agar to which $0.8 \mathrm{M} \mathrm{KCl}$ had been added as an osmoticum $(10 \mathrm{mM}$ nitrate was the sole nitrogen source). Plates were incubated at $28^{\circ} \mathrm{C}$ for $5-7 \mathrm{~d}$. Nitrate-utilizing colonies were subcultured on standard (e.g. non-stabilized) Czapek-Dox medium. The recipient strain used for the vector pJN1 was niaD57, whilst the recipient strain for the cosmid bank, pGFniaD, was niaD10.

Construction of a G. fujikuroi cosmid vector and genomic cosmid library. A $0.4 \mathrm{~kb}$ Pst I fragment containing the lambda cohesive ends was cloned into the Pst $\mathrm{I}$ site in the polylinker of vector $\mathrm{pJN} 1$ and the construct designated $\mathrm{pGFniaD}$. A library was constructed using DNA isolated from the wild-type (strain $\mathrm{m} 567$ ) inserted into pGFniaD. Complete digestion of the vector and partial digestion of genomic DNA was carried out using EcoRI, and the DNA was ligated and packaged using a standard kit (Amersham). The library was stored as 11185 individual Escherichia coli colonies.

\section{RESULTS}

\section{Isolation and subcloning of the niaD gene}

A library of a partial Sau3AI genomic DNA from strain m567 was generated in vector lambda EMBL3. This library, containing 25000 p.f.u., was screened by DNA:DNA hybridization with pSTA8 as a probe carrying the Aspergillus nidulans niaD gene (Johnstone et al., 1990). Twelve hybridizing lambda clones were revealed and their DNAs digested with a range of restriction enzymes. All twelve lambda clones were transformed into mutant strain niaD57. Lambda clone 11 gave the highest frequency of nitrate-utilizing transformants, yielding 12-15 transformants per $\mu$ g DNA. After Southern blotting, the $8.8 \mathrm{~kb}$ HindIII fragment from lambda clone 11 which showed hybridization to the probe was subcloned into pUC19. This vector was designated pJN1 (Fig. 1a).

\section{Gene and protein structure}

The $8.8 \mathrm{~kb}$ HindIII fragment of pJN1 containing the $G$. fujikuroi niaD gene (Fig. 1a) was partially sequenced. The nucleotide sequence and inferred amino acid sequence of the region containing niaD are shown in Fig. 1(b). The protein sequence is highly homologous to many other nitrate reductases (reviewed by Campbell \& Kinghorn, 1990), with haem-binding, flavin reductase and molybdenum cofactor domains. Overall, the G. fujikuroi deduced amino acid sequence shows the following homology with other fungal nitrate reductases: $94.5 \%$ to Fusarium oxysporum (Diolez et al., 1993), 58.8\% to Leptosphaeria maculans (Williams et al.,・1994), 58.7\% to Neurospora crassa (Okamoto et al., 1991), $54.4 \%$ to Aspergillus nidulans (Johnstone et al., 1990) and 36.2\% to Ustilago maydis (Banks et al., 1993). The G. fujikuroi gene is interrupted by only one putative intron, interrupting the

Fig. 1. (a) Restriction endonuclease map of the $8.8 \mathrm{~kb}$ Hindlll fragment of pJN1 containing the G. fujikuroi niaD gene (hatched) which was inserted into the HindIII site of pUC19 (not shown). The putative intron is indicated as a black box. (b) Nucleotide and inferred amino acid sequence of the $G$. fujikuroi niaD gene and its flanking regions. The putative intron is indicated in lower-case and by a break in the inferred amino acid sequence. $5^{\prime}$ and $3^{\prime}$ splicing sequences are underlined. The putative initiation codon is indicated in bold, as is the translational stop codon. Putative receptor motifs for the regulatory proteins NIT2/AREA (GATA) and the NIT4/NIRA (CTCCGNGG) in the promoter region of the niaD gene are underlined. TATA and CAAT motifs are overlined. A potential polyadenylation signal is also overlined. The chevrons above the sequence indicate a CT-rich motif typical of eukaryotic promoters. 
Table 1. Transformation frequencies using the G. fujikuroi niaD gene

The recipient strain for vector $\mathrm{pJN1}$ was niaD57 (derived from wild-type strain $\mathrm{m} 567$ ). The recipient strain for $\mathrm{pGFniaD}$ and the pGFniaD cosmid library was niaD10 (derived from kaurene oxidase mutant B1-41a).

\begin{tabular}{|ll|}
\hline Vector & $\begin{array}{c}\text { No. of transformants } \\
\text { per } \boldsymbol{\mu g} \text { DNA* }\end{array}$ \\
\hline PJN1 & $198,89,159,174$ \\
pGFniaD & $121,136,97$ \\
pGFniaD cosmid library & $141,182,102,126,82$ \\
\hline
\end{tabular}

*Each number represents the mean of three to five parallel transformations from individual consecutive experiments.

codon for amino acid residue 606. An identical situation exists only in $N$. crassa (Okamoto et al., 1991) and $F$. oxysporum (Diolez et al., 1993) in terms of intron number and position. The promoter region also includes a TATA box at $-124 \mathrm{bp}$ (relative to the proposed ATG), and five potential CAAT boxes, at $-67,-76,-85,-206$ and $-275 \mathrm{bp}$. The niaD gene is regulated by a wide-domain regulatory protein encoded by the nit-2 gene in $N$. crassa (Fu \& Marzluf, 1990) or are $A$ in $A$. nidulans (Kudla et al., $1990)$ as well as the pathway-specific inducible protein encoded by nit-4 in N. crassa (Fu et al., 1989) and nir $A$ in $A$. nidulans (Burger et al., 1991). The receptor binding sites for a NIT2/AREA binding protein (GATA) are present at $-8,-133,-331$ and $-587 \mathrm{bp}$. A receptor binding site for a NIT4/NIRA transcriptional factor (CTCCGNGG) is found in the G. fujikuroi niaD promoter at $-311 \mathrm{bp}$. In the $3^{\prime}$ non-translated sequence, a possible polyadenylation site located $295 \mathrm{bp}$ from the proposed translational stop codon is observed.

Nucleotide sequence analysis of the upstream region shows remarkable homology $(91.2 \%)$ with that of $F$. oxysporum (Diolez et al., 1993) for over 780 bases upstream from the translational start. Further upstream, there is no significant homology and similarly, in the $3^{\prime}$ non-coding region, significant homology does not exist.

\section{Homologous transformation}

Vector pJN1 containing the $8.8 \mathrm{~kb}$ HindIII insert harbouring the $G$. fujikuroi nia $D$ gene was introduced into the niaD 57 mutant strain, derived from wild-type strain $\mathrm{m} 567$, and transformants selected by growth on medium with nitrate as a nitrogen source. The frequency of nitrateutilizing colonies is given in Table 1. Frequencies as high as 200 transformants per $\mu \mathrm{g}$ DNA were observed and such frequencies were considered to be sufficient for selfcloning experiments. Consequently a cosmid vector was generated and its ability to transform the niaD10 strain (strain B1-41a/10 derived from a gibberellin-non-producing mutant) was confirmed (Table 1). Finally a genomic library was generated in vector $\mathrm{pGFniaD}$. The transformation frequencies using the cosmid library in pGFniaD in the niaD10 mutant background were similar and again sufficient for self-cloning. Transformation levels for both niaD strains were between 80 and 200 transformants per $\mu \mathrm{g}$ DNA. As the reversion frequency of both niaD57 and niaD10 mutants was low, less than 1 in 1000 nitrate-utilizing colonies, it is therefore likely that nitrate-utilizing colonies obtained in transformation experiments are indeed bona fide transformants.

Putative transformants were analysed at the molecular level. Initially ten nitrate-utilizing transformants of niaD10 produced using pGFniaD were examined by Southern blot hybridizations (data not shown). Of these, four showed disruption of the resident niaD band, indicative of homologous integration; one appeared unchanged compared with the recipient, as would be expected for gene conversion; while in the remaining transformants complex band patterns were obtained, suggesting multiple heterologous integrations. Following transformation of the niaD10 strain with the cosmid library, 15 colonies capable of growth on nitrate as sole nitrogen source were chosen at random for analysis of integration events by Southern blotting and hybridization (Fig. 2). The genomic DNA was digested with EcoRI and blots probed with the $2.6 \mathrm{~kb}$ PstI fragment of $\mathrm{pJN} 1$, containing most of the nia $D$ gene, or PstI-digested pUC19. Using the nia D probe, the resident $7.0 \mathrm{~kb}$ EcoRI band was visible in the recipient strain. Only two transformants (T2 and T13) showed a change in mobility of this band, giving in its place two bands, one of which also hybridized to the pUC19 probe, indicating homologous integration at the niaD site. Transformants $\mathrm{T} 5, \mathrm{~T} 7, \mathrm{~T} 8$ and $\mathrm{T} 9$ contained the $7 \cdot 0 \mathrm{~kb}$ niaD-hybridizing band, but there was no hybridization to the pUC19 probe. The reversion rate of the recipient strain is low, so it is likely that these strains represent double cross-over events, i.e. gene replacements, although this has not formally been proven. The remaining transformants, $\mathrm{T} 1, \mathrm{~T} 3, \mathrm{~T} 4, \mathrm{~T} 6, \mathrm{~T} 10, \mathrm{~T} 11, \mathrm{~T} 12$, T14 and T15, had the resident niaD band and in addition a band of $12.6 \mathrm{~kb}$ (this band is faint in Fig. 2 for T14 and T15), the size of the pGFniaD cosmid vector. As expected, this band also hybridized to pUC19. Since the cosmid inserts are EcoRI fragments, this pattern suggests integration at sites other than the niaD gene via the EcoRI library insert. Of the 15 transformants, therefore, six show homologous integration of cosmid DNA at the niaD site, while the remaining nine transformants have cosmid DNA integrated at ectopic (i.e. heterologous) sites.

\section{Electrophoretic karyotype determination}

To resolve and determine the number of $G$. fujikuroi chromosomes we used PFGE conditions which were suitable for the separation of the three Schizosaccbaromyces pombe chromosomes (Smith et al., 1987). The G. fujikuroi chromosomes were resolved into eight bands (Fig. 3). These were designated chromosomes I-VIII, ranging in size from 2 to $6 \mathrm{Mb}$. Chromosome I was around $6 \mathrm{Mb}$, chromosome II $5.7 \mathrm{Mb}$, chromosome III $5 \mathrm{Mb}$, chromosome IV 4.2 Mb. Chromosomes V, VI, VII and VIII 


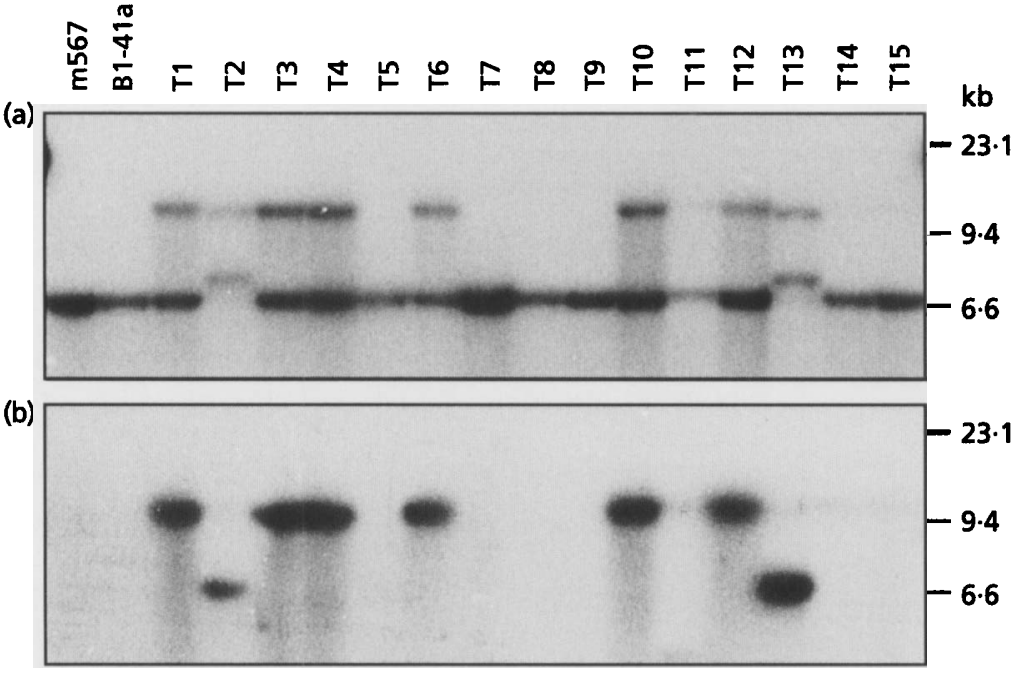

Fig. 2. Southern blot and DNA hybridization analysis of nia $D^{+}$transformants. Genomic DNA $(5 \mu \mathrm{g})$ from representative transformants obtained using the pGFniaD cosmid library was cleaved with EcoRI, which cuts the vector PGFniaD once. Following Southern blotting, filters were probed with the $2.6 \mathrm{~kb}$ Pstl G. fujikuroi niaD fragment (a) and linearized pUC19 (b). Lanes T1-T15 are representative transformants; $\mathrm{m} 567$ and $\mathrm{B1}$ 41a (left-hand lanes) are the recipient strains.

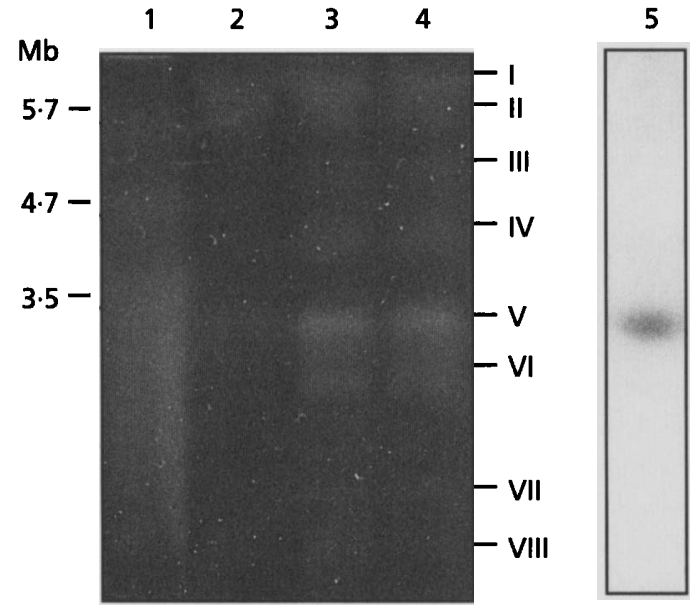

Fig. 3. Separation of intact $G$. fujikuroi chromosomal DNA. Lanes 2,3 and 4 have different concentrations of $G$. fujikuroi DNA. Lane 1 is commercially prepared chromosomal DNA from Schizosaccharomyces pombe. The sizes of the three S. pombe chromosomes are indicated on the left. Separated G. fujikuroi bands are tentatively given chromosome numbers I-VIII in descending order according to size as discussed in the text. Since the total $G$. fujikuroi genome size is not known, for example as determined by DNA:DNA reassociation analysis, the band values given in the text are only approximate. After electrophoresis the DNA was transferred to a filter and probed with the G. fujikuroi niaD gene (lane 5).

were less than $3.5 \mathrm{Mb}$ in size. Their approximate sizes were: chromosome $\mathrm{V}, 3 \cdot 2 \mathrm{Mb}$; chromosome VI, $3.0 \mathrm{Mb}$; and chromosomes VII and VIII, around $2.0 \mathrm{Mb}$. Chromosome $\mathrm{V}$ and chromosome VI showed higher relative intensity of ultraviolet fluorescence after ethidium bromide staining, suggesting that these bands represented more than one co-migrating chromosome, probably three in the case of chromosome $\mathrm{V}$ and two for chromosome VI. This would indicate that the chromosome number in G. fujikuroi strain $\mathrm{m} 567$ is at least 11 . Unfortunately there is no classical genetic or cytological determination avail- able to relate to this molecular karyotype. Given that $G$. fujikuroi has this (minimum) estimate of 11 chromosomes, the genome size would be at least $37 \mathrm{Mb}$, which is in line with genome sizes found in other ascomycetous filamentous fungi such as $A$. nidulans ( $31 \mathrm{Mb}$; Brody \& Carbon, 1989). The $8.8 \mathrm{~kb}$ HindIII fragment of pJN1 containing the G. fujikuroi niaD gene was radiolabelled to probe filters of resolved $G$. fujikuroi chromosomes. The niaD probe hybridized to chromosome $\mathrm{V}$. Recent work reported by Xu et al. (1995) on a number of strains of $G$. fujikuroi, but not including that used in this work (i.e. m567), indicates a haploid number of 12 chromosomes.

\section{DISCUSSION}

The results presented here report a significant increase in transformation frequency of $G$. fujikuroi using the homologous nitrate reductase (niaD) system rather than the heterologous systems reported previously (SanchezFernandez et al., 1991; Brückner et al., 1992). Such frequencies will enable the self-cloning of gibberellin biosynthetic genes by complementation of gibberellindefective mutants, including the kaurene oxidase defective strain used here. This notion is supported by the fact that transformation frequencies are similar (120-200 transformants per $\mu \mathrm{g}$ DNA) irrespective of whether the niaD vector alone or a cosmid genomic library is used, and independent of the genetic background of the recipient.

The fact that the niaD gene constructs have been shown to integrate at a relatively high frequency at homologous sites indicates that the system may be useful for gene disruption experiments. Several potential gibberellin genes have now been isolated (Appleyard et al., 1995; B. Tudzynski and co-workers, unpublished) and it should now be possible to test their involvement or role in gibberellin biosynthesis.

The niaD gene itself shows similarity to previously described fungal nitrate reductase genes. As expected, it has potential receptor nucleotide motifs for the global nitrogen regulator, NIT-2/AREA (e.g. GATA), as well 
as for the nitrate pathway-specific inducer, NIT-4/NIRA (i.e. CTCCGNGG). There is no indication, however, from hybridization or sequence analysis that the nitrite reductase gene nii $A$ is tightly linked to niaD (B. Tudzynski, unpublished), as has been found for a number of fungi.

Surprisingly, we observed high homology in the promoter regions of the G. fujikuroi and F. oxysporum niaD genes. $G$. fujikuroi is the perfect stage of the anamorph Fusarium section Liseola, and while it may be expected that members of the same genus would have high similarity in the coding regions of genes, it has not previously been reported that such high homology extends to the upstream regions. For example, other than the putative recognition motifs for regulatory proteins, there are no extensive stretches of nucleotide homology in the upstream sequences of the Aspergillus nidulans. A. niger (Unkles et al., 1992) or $A$. oryzae niaD genes (S. E. Unkles, unpublished). Further analysis of gene structure in these organisms is required in order to establish the significance of this apparently unique arrangement.

\section{ACKNOWLEDGEMENTS}

The work was supported by grants to B. T. from the German Science Foundation ( $\mathrm{Br}$ 1245/1-1) and to J.R.K. from the British Biotechnology and Biological Sciences Research Council (GR/H/20152). We also wish to thank Professor J. MacMillan (Long Ashton Research Station) for the kaurene oxidase defective mutant strain.

\section{REFERENCES}

Appleyard, V. C. L., Unkles, S. E., Legg, M. \& Kinghorn, J. R. (1995). Secondary metabolite production displayed. Mol $\&$ Gen Genet 247, 338-342.

Avalos, J., Casadesus, J. \& Cerda-OImedo, E. (1994). Gibberella fujikuroi mutants obtained with UV radiation and $N$-methyl- $N$ nitro-N-nitrosoguanidine. Appl Environ Microbiol 49, 187-191.

Banks, G. R., Shelton, P. A., Kanuga, N., Holden, D. W. \& Spanos, A. (1993). The Ustilago maydis narI gene encoding nitrate reductase activity: structural and transcriptional regulation. Gene 131, 69-78.

Bearder, J. R. (1983). In vivo diterpenoid biosynthesis in Gibberella fujikuroi: the pathway after ent-kaurene. In The Biochemistry and Physiology of Gibberellins, pp. 251-387. Edited by A. Crozier. New York: Praeger Publications.

Brody, H. \& Carbon, J. (1989). Electrophoretic karyotype of Aspergillus nidulans. Proc Natl Acad Sci US A 86, 6260-6263.

Bruckner, B. \& Blechschmidt, D. (1991a). The gibberellin fermentation. Crit Rev Biotechnol 11, 163-192.

Brückner, B. \& Blechschmidt, D. (1991b). Nitrogen regulation of gibberellin biosynthesis in Gibberella fujikuroi. Appl Microbiol Biotechnol 35, 646-650.

Bruckner, B., Unkles, S. E., Weltring, K.-M. \& Kinghorn, J. R. (1992). Transformation of Gibberella fujikuroi: effect of the Aspergillus nidulans AMA1 sequence on frequency and integration. Curr Genet 22, 314-316.

Bu'Lock, J. D., Detroy, R. W., Hostalek, Z. \& Munim-al-Shakarchi, A. (1974). Regulation of secondary metabolite biosynthesis in Gibberella fujikuroi. Trans Br Mycol Soc 62, 377-389.

Burger, G., Strauss, J., Scazzocchio, C. \& Lang, B. F. (1991). nir $A$, the pathway-specific regulatory gene of nitrate assimilation in
Aspergillus nidulans, encodes a putative GAL4-type zinc finger protein and contains four introns in highly conserved regions. Mol Cell Biol 11, 5746-5755.

Campbell, W. H. \& Kinghorn, J. R. (1990). Functional domains of assimilatory nitrate and nitrite reductases. Trends Biochem Sci 15, 315-319.

Candau, R., Avalos, J. \& Cerda-Olmedo, E. (1991). Gibberellins and carotenoids in the wild type and mutants of Gibberella fujikuroi. Appl Environ Microbiol 57, 3378-3382.

Candau, R., Avalos, J. \& Cerda-Olmedo, E. (1992). Regulation of gibberellin biosynthesis in Gibberella fujikuroi. Plant Physiol 100, 1184-1188.

Cove, D. (1976). Chlorate toxicity in Aspergillus nidulans: the selection and characterisation of chlorate-resistant mutants. Heredity 36, 191-203.

Diolez, A., Langin, T., Gerlinger, C., Brygoo, Y. \& Daboussi, M.-J. (1993). The nia gene of Fusarium oxysporum: isolation, sequence and development of a homologous transformation system. Gene 131, 61-67.

Fu, Y.-H. \& Marzluf, G. A. (1990). nit-2, the major positive-acting nitrogen regulatory gene of Neurospora crassa, encodes a sequencespecific DNA-binding protein. Proc Natl Acad Sci USA 87, 5331-5335.

Fu, Y.-H., Kneessi, J. Y. \& Marzluf, G. A. (1989). Isolation of nit-4, the minor regulatory gene which mediates nitrate induction in Neurospora crassa. J Bacteriol 171, 4067-4070.

Hedden, P., MacMillans, J. \& Phinnel, B. O. (1978). The metabolism of the gibberellins. Annu Rev Plant Pbysiol 29, 149-150.

Johnstone, I. L., MacCabe, P. C., Greaves, P., Cole, G. E., Brow, M. A. D., Gurr, S. J., Unkles, S. E., Clutterbuck, A. J., Kinghorn, J. R. \& Innis, M. A. (1990). Isolation and characterisation of the crnA-nii A-niaD gene cluster for nitrate assimilation in Aspergillus nidulans. Gene 90, 181-192.

Klittich, C. J. R. \& Leslie, J. F. (1988). Nitrate reduction mutants of Fusarium moniliforme (Gibberella fujikuroi). Genetics 118, 417-424.

Kudla, B., Caddick, M. X., Langdon, T., Martinez-Rossi, N. M., Bennett, C. F., Sibley, S., Davies, R. W. \& Arst, H. N. (1990). The regulatory gene are $A$ mediating nitrogen metabolite repression in Aspergillus nidulans. Mutations affecting specificity of gene activation alter a loop residue of a putative zinc finger. EMBO J 9, 1355-1364.

Okamoto, P. M., Fu, Y.-H. \& Marzluf, G. A. (1991). nit-3, the structural gene of nitrate reductase in Neurospora crassa: nucleotide sequence and regulation of mRNA synthesis and turnover. Mol $\&$ Gen Genet 227, 213-223.

Pitel, D. W., Vining, L. C. \& Arsenault, G. P. (1971a). Improved methods for preparing pure gibberellins from cultures of Gibberella fujikuroi. Isolation by adsorption or partition chromatography on silicic acid and by partition chromatography on Sephadex columns. Can J Biochem 49, 185-193.

Pitel, D. W., Vining, L. C. \& Arsenault, G. P. (1971b). Biosynthesis of gibberellins in Gibberella fujikuroi. The sequence after gibberellin GA4. Can J Biochem 49, 194-200.

Sambrook, J., Fritsch, E. F. \& Maniatis, T. (1989). Molecular Cloning : a Laboratory Manual, 2nd edn. Cold Spring Harbor, NY: Cold Spring Harbor Laboratory.

Sanchez-Fernandez, R., Unkles, S. E., Campbell, E. I., Macro, J. A., Cerda-Olmedo, E. \& Kinghorn, J. R. (1991). Transformation of the filamentous fungus Gibberella fujikuroi using the Aspergillus nidulans niaD gene encoding nitrate reductase. Mol \& Gen Genet 225, 231-233.

Smith, C. L., Matsumoto, T., Niwa, O., Klco, S., Fan, J.-B., Yanagida, M. \& Cantor, C. R. (1987). An electrophoretic karyotype 
for Schizosaccharomyces pombe by pulsed field gel electrophoresis. Nucleic Acids Res 15, 4481-4489.

Unkles, S. E., Campbell, E. I., Punt, P. J., Hawker, K. L., Contreras, R., Hawkins, A. R., van den Hondel, C. A. M. J. J. \& Kinghorn, J. R. (1992). The Aspergillus niger nia $D$ gene encoding nitrate reductase: upstream nucleotide and amino acid comparisons. Gene 111, 149-155.

Vass, R. C. \& Jeffries, E. G. (1979). Gibberellic acid. In Economic Microbiology: Secondary Products of Metabolism, pp. 421-435. Edited by A. H. Rose. New York: Academic Press.
Williams, R. S. B., Davis, M. A. \& Howlett, B. J. (1994). Nitrate reductase of the ascomycetous fungus, Leptosphaeria maculans: gene sequence and chromosomal location. Mol \& Gen Genet 244, 1-8.

Xu, J.-R., Yan, K., Dickman, M. B. \& Leslie, J. F. (1995). Electrophoretic karyotypes distinguish the biological species of Gibberella fujikuroi (Fusarium section liseola). Mol Plant-Microbe Interact 8, 74-84.

Received 27 July 1995; revised 17 October 1995; accepted 24 October 1995. 